\title{
Persistent Left Ventricular Dysfunction in Takotsubo Cardiomyopathy After Pacemaker Implantation
}

\author{
Satoshi Kurisu, MD; Ichiro Inoue, MD; Takuji Kawagoe, MD; Masaharu Ishihara, MD; \\ Yuji Shimatani, MD; Takaki Hata, MD; Yasuharu Nakama, MD; \\ Yasufumi Kijima, MD; Eisuke Kagawa, MD
}

\begin{abstract}
Two cases of takotsubo cardiomyopathy occurred after pacemaker implantation, both in elderly women who received a dual-chamber pacemaker for complete atrioventricular block. They had persistent left ventricular dysfunction even during their convalescence. (Circ J 2006; 70: 641-644)
\end{abstract}

Key Words: Gender; Pacemakers; Takotsubo cardiomyopathy

$A$ novel cardiac syndrome comprising transient left ventricular dysfunction with chest symptoms, electrocardiographic (ECG) changes and minimal myocardial enzymatic release has been gradually recognized worldwide ${ }^{1-5}$ and is known as takotsubo cardiomyopathy in Japan because the end-systolic left ventriculogram resembles a "takotsubo", which is a pot used for trapping octopuses. Patients with takotsubo cardiomyopathy have a favorable prognosis in general, because the left ventricular dysfunction is usually transient.

We report 2 cases of takotsubo cardiomyopathy associated with pacemaker implantation that presented as persistent left ventricular dysfunction even during the convalescent stage.

\section{Case Reports}

Case 1

An 89-year-old woman with hypertension and left hemiparesis was admitted to hospital with dizziness. She was conscious, her blood pressure was $130 / 70 \mathrm{mmHg}$, and pulse rate was 38 beats $/ \mathrm{min}$. Her hematological test results were normal, and chest X-ray showed no pulmonary edema or cardiac enlargement.

A 12-lead ECG showed sinus rhythm and complete atrioventricular block at a rate of 38 beats/min (Fig 1), and echocardiography showed normal left ventricular function (ejection fraction $=62 \%$ ). Next day, she received a dualchamber pacemaker under local anesthesia. The pulse generator was located in the left pectoral region, and the $52-\mathrm{cm}$ and $58-\mathrm{cm}$ bipolar leads were positioned in the low right atrial septum and mid right ventricular septum, respectively. No complications occurred during the operation.

She had chest discomfort 10 min after the operation, and her ECG showed significant ST-segment elevation in leads I, $\mathrm{aVL}$ and $\mathrm{V}_{2}-6$. Emergency coronary angiography showed

(Received December 14, 2005; revised manuscript received February 21, 2006; accepted February 24, 2006)

Department of Cardiology, Hiroshima City Hospital, Hiroshima, Japan

Mailing address: Satoshi Kurisu, MD, Department of Cardiology, Hiroshima City Hospital, 7-33 Moto-machi, Naka-ku, Hiroshima 730-8518, Japan. E-mail: skurisu@nifty.com no significant coronary artery disease, but left ventriculography showed akinesia of the mid-to-distal portion of the left ventricular chamber (ejection fraction $=38 \%$ ) (Fig 2). We diagnosed takotsubo cardiomyopathy. She had congestive heart failure that required intravenous furosemide. Creatine phosphokinase increased to $613 \mathrm{IU} / \mathrm{L} 20 \mathrm{~h}$ after the operation.

Follow-up echocardiography 2 months later showed persistent akinesia of the mid-to-distal portion of the left ventricular chamber. Serial ECG showed resolution of the ST-segment elevation, but there was not deep $\mathrm{T}$ wave inversion under ventricular pacing.

Case 2

A 77-year-old woman with hypertension and diabetes was admitted to hospital with dyspnea on effort. She was conscious, her blood pressure was $140 / 80 \mathrm{mmHg}$, and pulse rate was 30 beats/min. Her hematological test results were normal, and chest X-ray showed no pulmonary edema or cardiac enlargement.

A 12-lead ECG showed sinus rhythm and complete atrioventricular block at a rate of 30 beats/min (Fig 3), and echocardiography showed normal left ventricular function (ejection fraction $=75 \%$ ) (Fig 4). She also received a dualchamber pacemaker under local anesthesia, with the pulse generator located in the left pectoral region and the $52-\mathrm{cm}$ and $58-\mathrm{cm}$ bipolar leads positioned in the right atrial appendage and right ventricular apex, respectively. No complications occurred during the operation.

She had no chest symptom immediately after the operation, orthopnea developed 3 days later, and the ECG showed significant ST-segment elevation in leads V2-6. Echocardiography showed akinesia of the mid-to-distal portion of the left ventricular chamber (ejection fraction $=27 \%$ ). She had congestive heart failure that required intravenous furosemide.

She was re-admitted with orthopnea 3 months later. Coronary angiography showed no significant coronary artery disease, but left ventriculography showed persistent akinesia of the mid-to-distal portion of the left ventricular chamber (ejection fraction $=22 \%$ ). We diagnosed takotsubo cardiomyopathy.

Follow-up echocardiography 4 months later showed persistent akinesia of the mid-to-distal portion of the left 


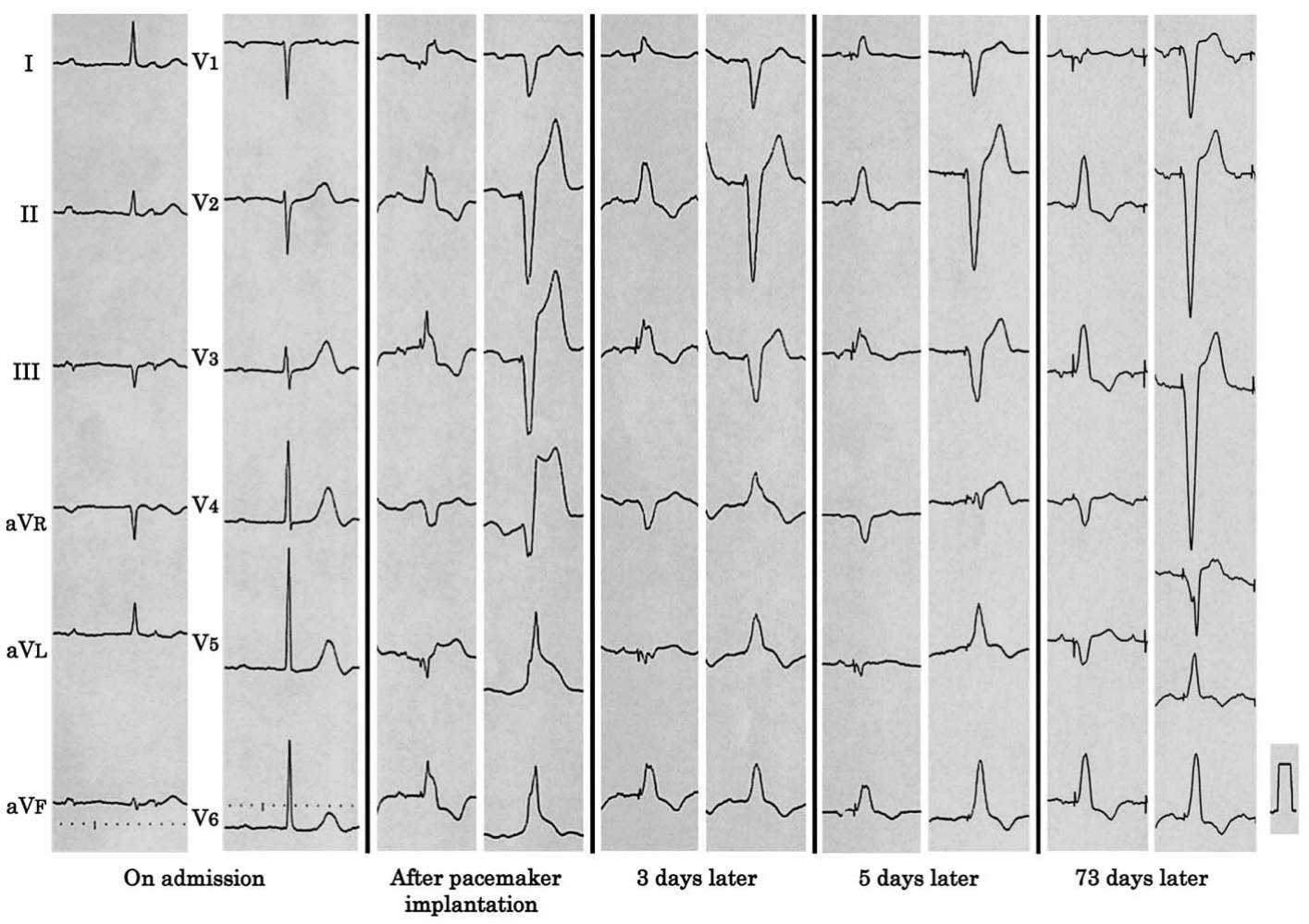

Fig 1. Case 1. Time course of the 12-lead electrocardiograms. The recording immediately after the operation shows significant ST-segment elevation in leads I, aVL and $\mathrm{V}_{2-6 .}$

A

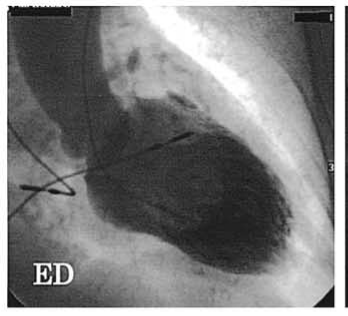

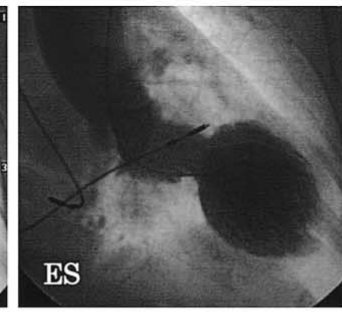
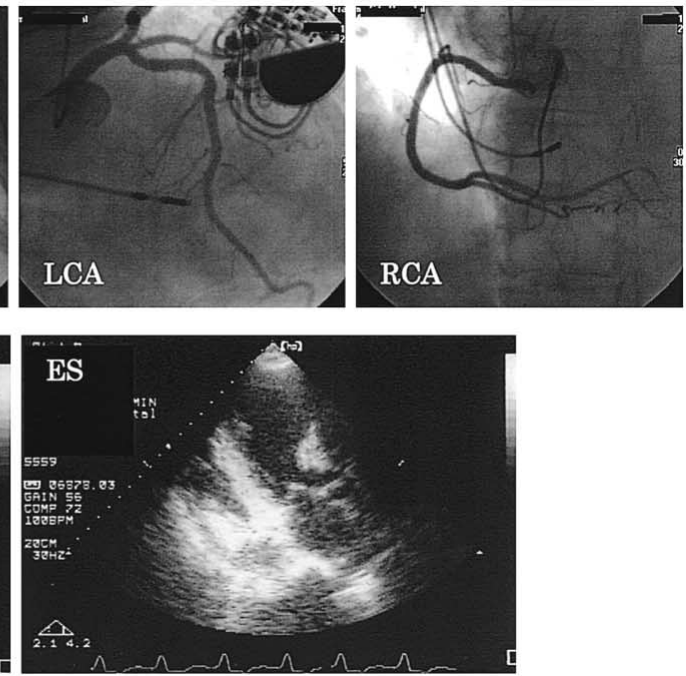

Fig 2. Case 1. (A) Coronary angiography does not show significant coronary artery disease, but left ventriculography shows akinesia of the mid-to-distal portion of the left ventricular chamber. (B) Follow-up echocardiography 2 months later shows persistent akinesia of the mid-to-distal portion of the left ventricular chamber. ED, end-diastole; ES, endsystole; LCA, left coronary angiogram; RCA, right coronary angiogram.

ventricular chamber. Serial ECG showed resolution of ST-segment elevation, but deep $\mathrm{T}$ wave inversion under ventricular pacing did not occur.

\section{Discussion}

There are several complications of permanent pacemaker implantation, such as dislocation of endocardial leads, infections of the generator and/or leads, and skin ulcerations 6 Perforation of leads and cardiac tamponade are very rare, but fatal. Based on our case reports we consider that takotsubo cardiomyopathy is a possible complication of permanent pacemaker implantation.

Since Sato et al first reported takotsubo cardiomyopathy in 1990, several clinical features have been identified!-5 Most patients are women (range, $82 \%^{3}$ to $100 \% 5$ ), and the mean age is $62^{4}$ to $74^{3}$ years. In addition, patients often experience emotional or physical stress antecedent to the 


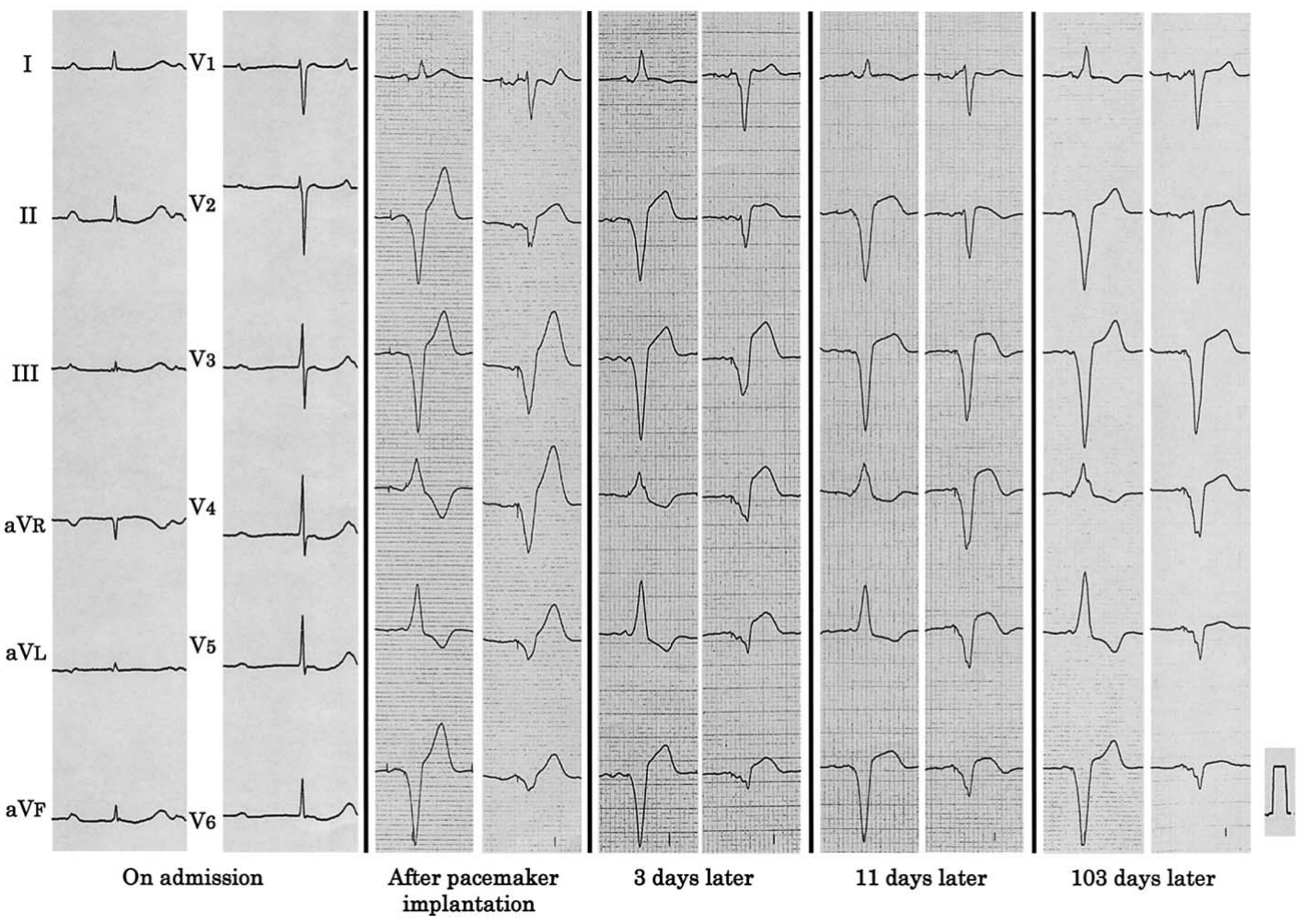

Fig 3. Case 2. Time course of the 12-lead electrocardiograms. The recording 3 days after operation shows significant ST-segment elevation in leads $\mathrm{V}_{2-6}$.

A
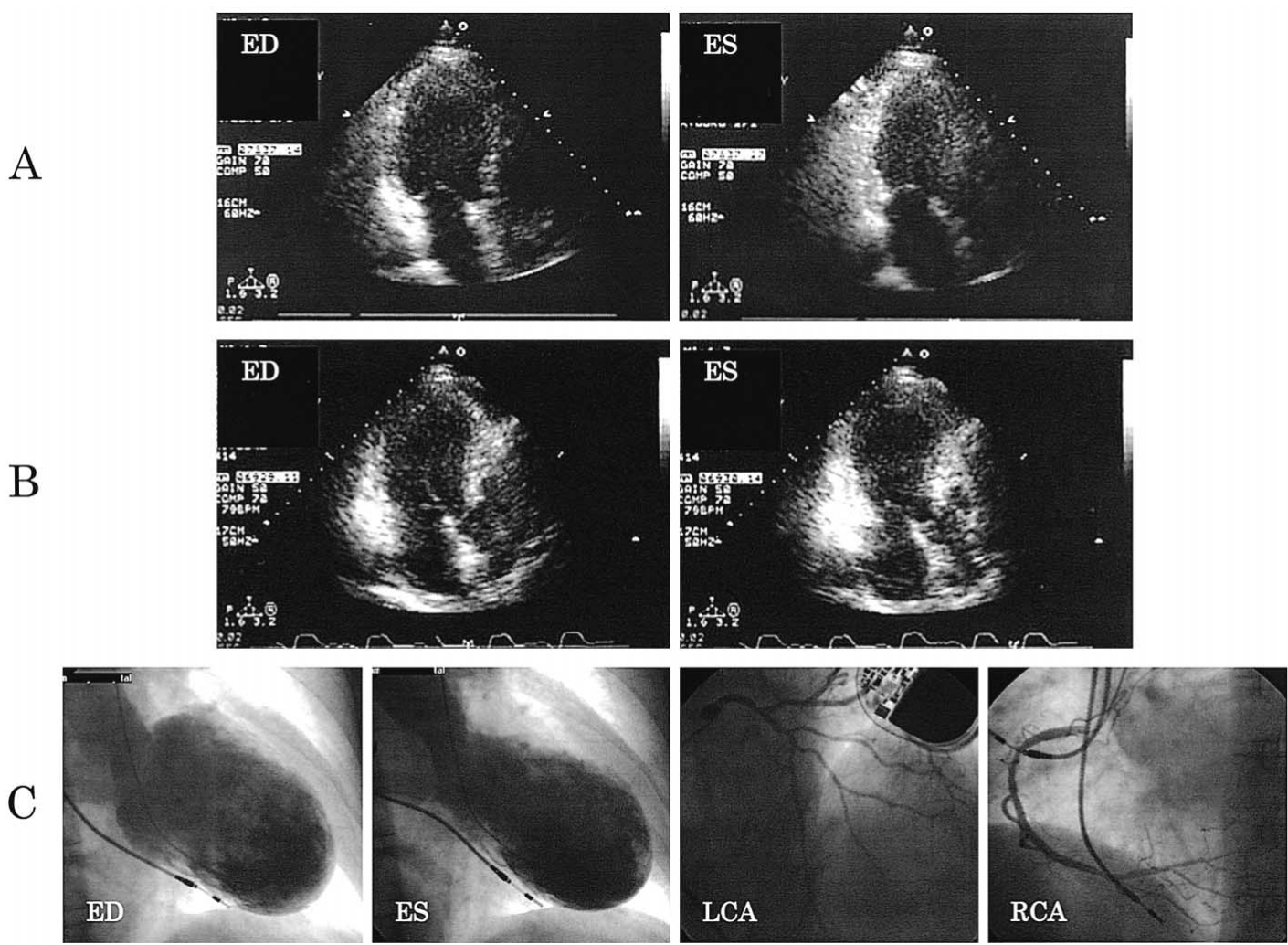

Fig 4. Case 2. (A) Echocardiography on admission shows normal left ventricular function, but 3 days later (B) there is akinesia of the mid-to-distal portion of the left ventricular chamber. (C) Three months later, coronary angiography does not show significant coronary artery disease, but left ventriculography shows persistent akinesia of the mid-to-distal portion of the left ventricular chamber. ED, end-diastole; ES, end-systole; LCA, left coronary angiogram; RCA, right coronary angiogram. 
occurrence of takotsubo cardiomyopathy. In the present cases, acute stress during the operation may have precipitated takotsubo cardiomyopathy.

Although the precise mechanism of takotsubo cardiomyopathy remains unclear, several possible mechanisms have been proposed, including multivessel epicardial coronary spasm ${ }^{2}$ microvascular coronary spasm ${ }^{2}$ and catecholamine-mediated toxicity? The striking predominance of women suggests that sex hormones may exert an important influence?

The most interesting finding of our report is the persistent akinesia of the mid-to-distal portion of the left ventricular chamber, although the precise reason remained unclear. Previous animal studies have shown that ventricular pacing can cause myofibrillar cellular disarray, dystrophic calcifications, prominent subendocardial Purkinje cells and an increase in variable-sized, disorganized mitochondria? Thus, one possible mechanism is that ventricular pacing-induced histologic changes are associated with persistent left ventricular dysfunction in takotsubo cardiomyopathy. It was recently demonstrated that ventricular pacing can cause left ventricular mechanical dyssynchrony and subsequent remodeling, so another possibility is ventricular pacing-induced mechanical dyssynchrony.

Another interesting finding was that the ECG showed ST-segment elevation during the early phase, but without deep T wave inversion during the follow-up under ventricular pacing, which is opposite to previously reported ECG characteristics. We consider that the lack of deep T wave inversion may be a maker of an adverse outcome in takotsubo cardiomyopathy. Regrettably, we did not obtain ECG recordings after pacemaker implantation under the patients' own heart beat.

Cardiologists should recognize that takotsubo cardiomyo- pathy is a possible complication of permanent pacemaker implantation in elderly women. Because it is impossible to predict the occurrence of takotsubo cardiomyopathy, cardiologists must pay attention to ECG changes during and after the operation. It remains unclear whether anxiolytic medications immediately before the operation may help to prevent the occurrence of takotsubo cardiomyopathy.

\section{References}

1. Sato H, Tateishi H, Uchida T, Dote K, Ishihara M. Tako-tsubo-like left ventricular dysfunction due to multivessel coronary spasm. In: Kodama K, Haze K, Hori M, editors. Clinical aspect of myocardial injury: From ischemia to heart failure. Tokyo: Kagakuhyoronsha Publishing Co; 1990; 56-64 (in Japanese).

2. Kurisu S, Sato H, Kawagoe T, Ishihara M, Shimatani Y, Nishioka K, et al. Tako-tsubo-like left ventricular dysfunction with ST segment elevation: A novel cardiac syndrome mimicking acute myocardial infarction. Am Heart J 2002; 143: 448-455.

3. Abe Y, Kondo M, Matsuoka R, Araki M, Dohyama K, Tanio H. Assessment of clinical features in transient left ventricular apical ballooning syndrome. J Am Coll Cardiol 2003; 41: 737-742.

4. Desmet WJ, Adriaenssens BF, Dens JA. Apical ballooning of the left ventricle: First series in white patients. Heart 2003; 89: 1027-1031.

5. Wittstein IS, Thiemann DR, Lima JA, Baughman KL, Schulman SP, Gerstenblith G, et al. Neurohumoral features of myocardial stunning due to sudden emotional stress. N Engl J Med 2005; 352: 539-548.

6. Parsonnet V, Bernstein AD, Lindsay B. Pacemaker-implantation complication rates: An analysis of some contributing factors. $J \mathrm{Am}$ Coll Cardiol 1989; 13: 917-921.

7. Ueyama T, Hano T, Kasamatsu K, Yamamoto K, Tsuruo Y, Nishio I. Estrogen attenuates the emotional stress-induced cardiac responses in the animal model of tako-tsubo (ampulla) cardiomyopathy. J Cardiovasc Pharmacol 2003; 42: S117-S119.

8. Karpawich PP, Justice CD, Cavitt DL, Chang CH. Developmental sequelae of fixed-rate ventricular pacing in the immature canine heart: An electrophysiologic, hemodynamic, and histopathologic evaluation. Am Heart J 1990; 119: 1077-1083.

9. Sweeney MO, Prinzen FW. A new paradigm for physiologic ventricular pacing. J Am Coll Cardiol 2006; 47: 282-288. 